\title{
LVRT of Grid Interfaced Variable Speed Driven PMSG for WECS during Fault
}

\author{
Rajveer Mittal, K.S.Sandhu, D.K.Jain
}

\begin{abstract}
Wind energy conversion systems have become a focal point in the research of renewable energy sources. This is in no small part due to the rapid advances in the size of wind generators as well as the development of power electronics and their applicability in wind energy extraction. The voltage of the direct driven permanent magnet wind generators (PMSG) is variable due to the intermittent nature of the wind energy. Fluctuating voltage and power is of major concern in the converter based grid connected wind generation systems. An inverter is essential for the interfacing of the wind source with the AC network. This paper discusses the interconnection issues of permanent magnet wind generators to local grid as per prevailing grid standards during healthy and fault conditions. The fault ride-through topology for PMSG has been demonstrated using MATLAB Simulink based simulation.
\end{abstract}

Index Terms-Variable Speed Control, Wind Energy Conversion System, PMSG, Low Voltage Ride-through (LVRT), Power Quality.

\section{INTRODUCTION}

Wind energy is a reliable, natural and renewable electrical power supply. The high installed capacity of today's wind turbines and decreasing plant costs have shown that wind power can be competitive with conventional, more heavily polluting, fuels in the long term. Wind power growth with a $20 \%$ annual rate has experienced the fastest growth among all renewable energy sources science five years ago. It is predicted that by 2020 up to $12 \%$ of the world's electricity will have been supplied by wind power. Figure- 1 shows the global cumulative installed capacity and global annual installed capacity.

In terms of wind power generation technology, as a result of numerous technical benefits (higher energy yield, reducing power fluctuations and improving var supply) the modern MW-size wind turbines always use variable speed operation which is achieved by electrical converters .These converters are typically associated with individual generators and they contribute significantly to the costs of wind turbines. Between variable speed wind turbine generators doubly fed induction generators (DFIGs) and permanent magnet synchronous generators (PMSGs) with primary converters are emerging as the preferred technologies.

Rajveer Mittal is with the Department of Electrical and Electronics Engineering, Maharaja Agrasen Institute of Technology, Rohini,Delhi, India K.S Sandhu is with the Department of Electrical Engineering, National Institute of Technology, Kurukshetra, Haryana, India.

D. K. Jain is with the Guru Prem Sukh Memorial College of engineering under GGSIP University, Delhi, India.
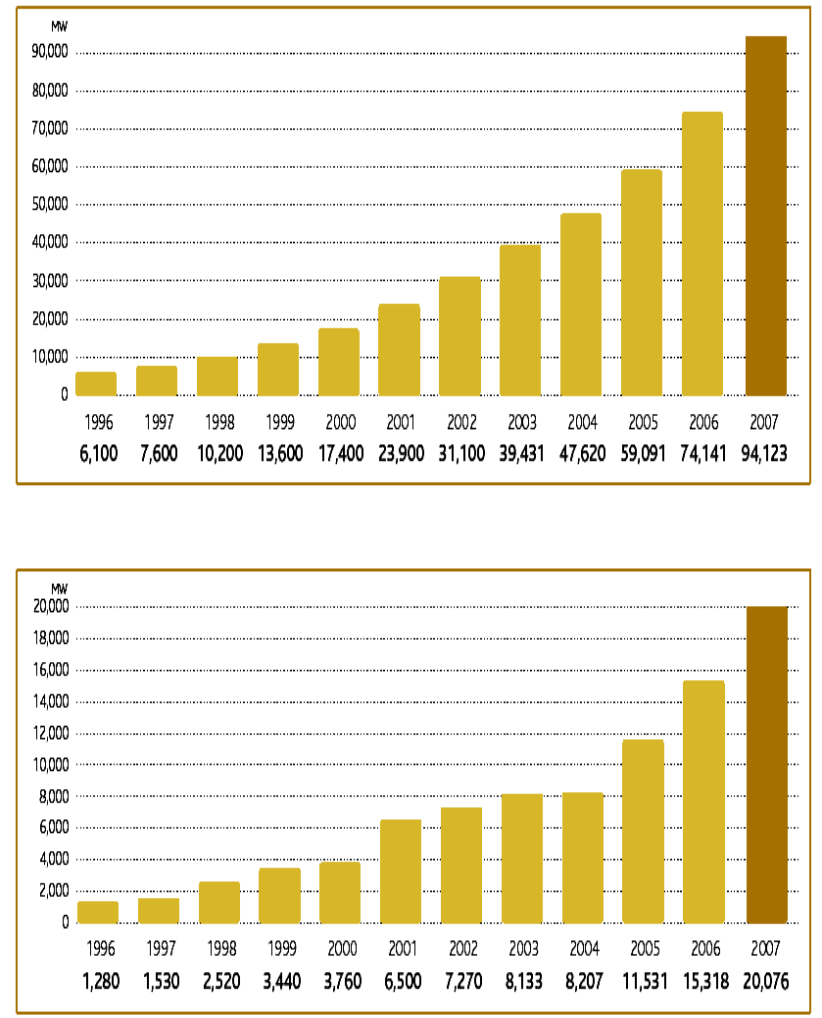

Fig.1: Global Cumulative Installed Capacity and Global Annual Installed Capacity

As a result of large-scale wind power generation, interconnecting large wind farms to power grids and the relevant influences on the host grids need to be carefully investigated. Wind farms are now required to comply with stringent connection requirements including reactive power support, transient recovery, system stability and voltage/frequency regulation. Further to increase the maximum power extraction the variable speed generators are employed. These variable speed generators necessitate a AC-DC-AC conversion systems. The generator side converter controls the electromagnetic torque, and therefore the extracted power, while the grid side converter controls both the DC link voltage and the power factor. Moreover, when designing the control strategy, it seems that the generator-side converter must control the extracted power as it is located closer to the incoming power. Hence, the grid-side converter would control the DC voltage.

Fulfilling the new grid codes constitutes one of the main challenges for the wind power industry. There are ride through requirements. Enhancing the operation of wind turbines in front of the grid faults is mandatory requirement. 
The wind turbines must stay connected to the grid during grid disturbances. They should continuously feed the reactive power in addition to limited active power. In modern wind turbines the increasing integration of power electronics enable to control the behavior of wind generation system under faulty scenarios. [1-5]

In this paper, first, the grid connections requirements are listed as per IEEE standards. The system modeling for ride-through capability of the PMSG during fault condition is presented. Finally, the MATLAB Simulink based is used to validate the proposed ride-through topology.

\section{MAJOR GRID PROBLEMS}

In Europe, substantial wind penetration exists today and will only increase over time. The impacts on the transmission network are viewed not as an obstacle to development, but rather as obstacles that must be overcome. High penetration of intermittent wind power (greater than 20 percent of generation meeting load) and may affect the network in the following ways and has to be studied in detail:

\section{A. Poor grid stability}

For economic exploitation of wind energy, a reliable grid is as important as availability of strong winds. The loss of generation for want of stable grid can be $10 \%$ to $20 \%$ and this deficiency may perhaps be the main reasons for low actual energy output of WEGs compared to the predicted output in known windy areas with adequate wind data.

\section{B. Low-frequency operation}

Low frequency operation affects the output of WEGs in two ways. Many WEGs do not get cut-in, when the frequency is less than $48 \mathrm{~Hz}$ (for standard frequency of $50 \mathrm{~Hz}$ ) through wind conditions are favorable, with consequent loss in output. This deficiency apart, the output of WEGs at low frequency operation is considerably reduced, due to reduced speed of the rotor. The loss in output could be about 5 to $10 \%$ on the account of low frequency operation.

\section{Impact of low power factor}

WEGs fitted with induction generators need reactive power for magnetizing. Normally in conventional energy systems, generators apart from supplying active power will be supplying a reactive power. But in case of WEGs fitted with induction generators, instead of supplying reactive power they absorb reactive power from the grid, which undoubtedly is a strain on the system. Suitable reactive power compensation may be required to reduce the reactive power burden on the grid.

\section{Power flow}

It is to be ensured that the interconnecting transmission or distribution lines will not be over-loaded. This type of analysis is needed to ensure that the introduction of additional generation will not overload the lines and other electrical equipment. Both active and reactive power requirements should be investigated.

\section{E. Short circuit}

It is required to determine the impact of additional generation sources to the short circuit current ratings of existing electrical equipment on the network.

\section{F. Power Quality}

Fluctuations in the wind power may have direct impact on the quality of power supply. As a result, large voltage fluctuations may result in voltage variations outside the regulation limits, as well as violations on flicker and other power quality standards.

\section{WIND TURBINE TECHNOLOGIES FOR GRID REQUIREMENTS}

In this Section a brief review is presented of wind turbine technology aspects, associated with grid code compliance. Wind turbines are generally divided in two main technological categories:

1. Constant speed wind turbines, which are equipped with squirrel cage induction generators directly connected to the grid. The rotational speed of the rotor is practically fixed, since they operate at a slip around $1 \%$. Since the induction machine absorbs reactive power from the grid, connection of compensating capacitor banks at the wind turbine (or wind farm) terminals is necessary. Their aerodynamic control is based on stall, active stall or pitch control. A variation of this scheme utilizes a wound rotor induction generator and electronically controlled external resistors to the rotor terminals, permitting a very variation of speed (typically up to $10 \%$ above synchronous).

2. Variable speed wind turbines, the rotor speed of which varies significantly, according to the prevailing wind conditions. Two major types are available: The first is utilizes a Doubly-Fed Induction Generator (DFIG) and a rotor converter cascade of reduced rating, while the second employs a synchronous or induction generator, the stator of which is interfaced to the grid via a full-power converter.

In case of DFIGs the generator's stator is directly connected to the grid while the rotor is connected through a cascade of two voltage source converters (rectifier-inverter, connected back-to-back). Wind turbines with full converter use either a synchronous or an asynchronous generator, whose stator is connected to the grid via an AC/DC/AC converter cascade. In this case, the converter handles the total generator power to the grid and therefore no size economies are possible.

The latest grid codes require that wind farms must remain in operation during severe grid disturbances, ensure fast restoration of active power to the prefault levels, as soon as the fault is cleared, and in certain cases produce reactive current in order to support grid voltage during disturbances. Depending on their type and technology, wind turbines can fulfill these requirements to different degrees, as explained in the following. Starting with constant speed wind turbines, their low voltage behavior is dominated by the presence of the grid-connected induction generator. In the event of a voltage dip, the generator torque reduces considerably (roughly by the square of its terminal voltage) resulting in the acceleration of the rotor, which may result in rotor instability, unless the voltage is restored fast or the accelerating mechanical torque is rapidly reduced. Further, operation of the machine at increased slip values results in increased reactive power absorption, particularly after fault clearance 
and partial restoration of the system voltage. This effectively prevents fast voltage recovery and may affect other neighboring generators, whose terminal voltage remains depressed. Since the dynamic behavior of the induction generator itself cannot be improved, measures that can be taken in order to enhance the fault ride-through capabilities of constant speed wind turbines are the following:

$\ddot{y}$ Improvement in the response of the wind turbine aerodynamic control system, in order to perform fast limitation of the accelerating mechanical torque, to prevent rotor overspeed. Physical limitations of the blades and the pitch regulation mechanism impose a limit on the effectiveness of such an approach.

$\ddot{y}$ Supply of reactive power through static compensation devices at the wind turbine or wind farm terminals, such as SVCs or STATCOMs. These device would provide high amounts of reactive power during faults, to effectively support the terminal voltage and therefore limit the magnitude of the voltage dip experienced by the wind turbines. Nevertheless, FACTS are complicated and costly devices, while there is an obvious limitation to the voltage correction they can achieve, particularly in the event of nearby system faults.

Variable speed wind turbines, on the other hand, present the distinct advantages of direct generator torque and reactive current control and the possibility to endure large rotor speed variations without stability implications. For this reason, grid disturbances affect much less their operation and, generally speaking, they are capable of meeting stringent requirements.

In case of voltage disturbances, rotor over speed becomes an issue of much smaller significance, since a limited increase of speed is possible (e.g. 10-15\% above rated), the rotor inertia acting as an energy buffer for the surplus accelerating power, until the pitch regulation becomes effective. In case of severe voltage dips, an energy surplus may occur in the electrical part, potentially leading to dc over voltages. This is dealt with via proper redesign of the converter controllers, increase of the local energy storage capacity (e.g. capacitor size) or even by providing local power dissipation means.

However, even with variable speed wind turbines there still exist LVRT issues affecting their response. In the case of DFIG wind turbines, the direct connection of the generator stator to the grid inevitably results in severe transients in case of large grid disturbances. Hence, the stator contributes a high initial short circuit current, while large currents and voltages are also induced in the rotor windings, as a consequence of the fundamental flux linkage dynamics of the generator. Furthermore, the depressed terminal voltage reduces accordingly the power output of the grid side rotor converter, leading to an increase of the dc bus capacitor voltage. To protect the power converters from over voltages and over currents, DFIGs are always equipped with a device known as a crowbar, that short circuit the rotor terminals as soon as such situations are detected. Once the crowbar is activated, the DFIG behaves like a conventional induction machine, i.e. control is lost over the generator. Notably, crowbar activation is possible not only at the instant of a voltage depression, but also in case of abrupt voltage recovery, after clearance of a fault. Conceptually, two crowbar options are available:

- The passive crowbar, utilizing a diode rectifier or a pair of antiparallel thyristors to short the rotor terminals. The disadvantage of this option is the lack of control on the deactivation of the crowbar, leading to sustained operation with short-circuited rotor.

- The active crowbar that uses IGBT switches to short the rotor. This enhances considerably the operation of the device, with a faster elimination of the rotor transients (typically within $100 \mathrm{~ms}$ ) and therefore faster regain of control. After deactivation of the crowbar, full controllability over the wind turbine behavior is resumed.

Hence, although voltage dips inevitably cause torque and power transients in the DFIG wind turbine, which excite the rotor crowbar protection for a limited time interval, the various implementations of the active crowbar can improve the stability of the wind turbine and its response to sudden voltage changes.

Variable speed wind turbines with full power converters present the distinct advantage that the converter totally decouples the generator from the grid. Hence, grid disturbances have no direct effect on the generator, whose current and torque variations during voltage dips are much lower compared to the DFIG and the respective transients fade out faster, [6-8]. From the point of view of the reactive output power, the grid side converter has the ability to produce reactive current during the voltage dip, up to its rated current. Notably, this wind turbine type may exhibit better voltage control capabilities even than conventional synchronous generators.

Another notable advantage of this type against the DFIG-based wind turbines is related with the behavior of the latter in case of unbalanced disturbances. In such situations, the low negative sequence impedance of the induction generator may give rise to large rotor currents, whose frequency lies outside the controllers' bandwidth, resulting in the activation of the crowbar (or the disconnection of the stator) until the disturbance is cleared. Wind turbines can control their active power output by pitch control, while variable speed wind turbines have the additional capability for such control via variation of their rotor speed. Hence, power curtailment, ramp rate limitations and contribution to frequency regulation is possible, even for constant speed machines. In the latter case, however, the grid frequency is directly related to the generator slip and hence a change in frequency will transiently affect the active power produced by the wind turbine. In the case of variable speed machines, on the other hand, the generator power is directly controlled and therefore their primary frequency response is entirely adjustable via proper design of the control systems.

\section{FAULT RIDE THROUGH REQUIREMENTS}

The large increase in the installed wind capacity in transmission systems necessitates that wind generation remains in operation in the event of network disturbances. For this reason, grid codes issued during the last years invariably demand that wind farms (especially those 
connected to $\mathrm{HV}$ grids) must withstand voltage dips to a certain percentage of the nominal voltage (down to $0 \%$ in some cases) and for a specified duration. Such requirements are known as Fault Ride Through (FRT) or Low Voltage Ride Through (LVRT) and they are described by a voltage vs. time characteristic, denoting the minimum required immunity of the wind power station. The FRT requirements also include fast active and reactive power restoration to the prefault values, after the system voltage returns to normal operation levels. Some codes impose increased reactive power generation by the wind turbines during the disturbance, in order to provide voltage support, a requirement that resembles the behavior of conventional synchronous generators in over-excited operation. The requirements depend on the specific characteristics of each power system and the protection employed and they deviate significantly from each other.

The required fault behavior of a wind farm can be summarized into four requirements:

- . For system faults that last up to $140 \mathrm{~ms}$, the wind farm has to remain connected to the network. For supergrid voltage dips of duration greater than 140 $\mathrm{ms}$, the wind farm has to remain connected to the system for any dip-duration on or above the heavy black line of fig. 2 .

- During system faults and voltage sags, a wind farm has to supply maximum reactive current to the Grid System without exceeding the transient rating of the plant.

- For system faults that last up to $140 \mathrm{~ms}$, upon the restoration of voltage to $90 \%$ of nominal, a wind farm has to supply active power to at least $90 \%$ of its pre-fault value within $0.5 \mathrm{sec}$. For voltage dips of duration greater than $140 \mathrm{~ms}$, a wind farm has to supply active power to at least $90 \%$ of its pre-fault value within $1 \mathrm{sec}$ of restoration of voltage to $90 \%$ of nominal.

- During voltage dips lasting more than $140 \mathrm{~ms}$, the active power output of a wind farm has to be retained at least in proportion to the retained balanced super grid voltage. [8,9]

It should be noted that in cases where less than $5 \%$ of the turbines are running, or under very high wind speed conditions where more than $50 \%$ of the turbines have been shut down, a wind farm is permitted to trip.

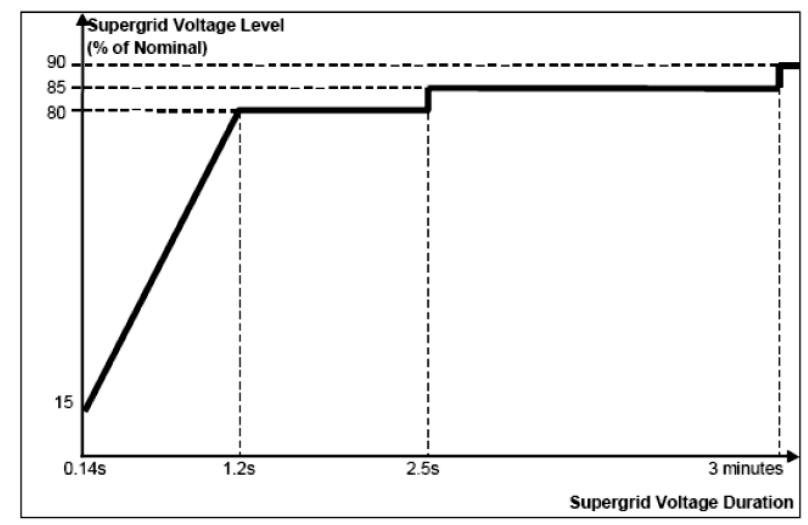

Fig.2: Required ride through capability of wind farms for super grid voltage dips of duration greater than $140 \mathrm{~ms}$

\section{WIND TURBINE GENERATION TECHNOLOGIES}

The function of an electrical generator is providing a means or energy conversion between the mechanical torque from the wind rotor turbine, as the prime mover, and the local load or the electric grid. Different types of generators are being used with wind turbines. Small wind turbines are equipped with DC generators of up to a few kilowatts in capacity. Modern wind turbine systems use three phase AC generators [9-10]. The common types of AC generator that are possible candidates in modern wind turbine systems are as follows:

\section{Squirrel-Cage (SC) rotor Induction Generator (IG), Wound-Rotor (WR) Induction Generator, \\ Doubly-Fed Induction Generator (DFIG),}

Synchronous Generator (With external field excitation),

\section{- Permanent Magnet (PM) Synchronous Generator.}

For assessing the type of generator in WECS, criteria such as operational characteristics, weight of active materials, price, maintenance aspects and the appropriate type of power electronic converter, are used.

Historically, induction generator (IG) has been extensively used in commercial wind turbine units. Asynchronous operation of induction generators is considered an advantage for application in wind turbine systems, because it provides some degree of flexibility when the wind speed is fluctuating. There are two main types of induction machines: squirrel cage (SC), and wound rotor.

Another category of induction generator is the doubly fed induction generator (DFIG). The DFIG may be based on the squirrel-cage or wound-rotor induction generator.

The induction generator based on Squirrel-Cage rotor (SCIG) is a very popular machine because of its low price, mechanical simplicity, robust structure, and resistance against disturbance and vibration. The wound-rotor is suitable for speed control purposes. By changing the rotor resistance, the output of the generator can be controlled and also speed control of the generator is possible. Although wound rotor induction generator has the advantage described above, it is more expensive than a squirrel-cage rotor.

The Doubly-Fed Induction Generator (DFIG) is a kind of induction machine in which both the stator windings and the rotor windings are connected to the source. The rotating winding is connected to the stationary supply circuits via power electronic converter. The advantage of connecting the converter to the rotor is that variable-speed operation of the turbine is possible with a much smaller and therefore much cheaper converter. The power rating of the converter is often about $1 / 3$ the generator rating [11-14].

Another type of generator that has been proposed for wind turbines in several research articles is synchronous generator. This type of generator has the capability of direct connection (direct-drive) to wind turbines, with no gearbox. This advantage is favorable with respect to lifetime and maintenance. Synchronous machines can use either electrically excited or permanent magnet (PM) rotor.

The PM and electrically-excited synchronous generators differ from the induction generator in that the magnetization is provided by a Permanent Magnet pole system or a dc 
supply on the rotor, featuring providing self-excitation property. Self-excitation allows operation at high power factors and high efficiencies for the PM synchronous. It is worth mentioning that induction generators are the most common type of generator use in modern wind turbine systems [14-16].

A comparison between the variable speed wind turbine and the constant speed wind turbine shows that variable speed reduce mechanical stresses: gusts of wind can be absorbed, dynamically compensate for torque and power pulsations caused by back pressure of the tower. This backpressure causes noticeable torque pulsations at a rate equal to the turbine rotor speed times the number of rotor blades. The used of a doubly fed induction generator in WECS with the rotor connected to the electric grid through an AC-AC converter offers the following advantages:

$\ddot{y} \quad$ only the electric power injected by the rotor needs to be handled by the convert, implying a less cost AC-AC converter;

$\ddot{y}$ improved system efficiency and power factor control can be implemented at lower cost, the converter has to provide only excitation energy .

Hence, taking advantage of power electronic advances in recent years, WECS equipped with doubly fed induction generator systems for variable speed wind turbine are one of the most efficient configurations for wind energy conversion.[17-18]

The advantages of PM machines over electrically excited machines can be summarized as follows according to literatures:

$\ddot{y} \quad$ higher efficiency and energy yield,

$\ddot{y}$ no additional power supply for the magnet field excitation,

$\ddot{y}$ improvement in the thermal characteristics of the PM machine due to the absence of the field losses,

$\ddot{y} \quad$ higher reliability due to the absence of mechanical components such as slip rings,

$\ddot{y} \quad$ lighter and therefore higher power to weight ratio.

However, PM machines have some disadvantages, which can be summarized as follows:

$\ddot{y} \quad$ high cost of PM material,

$\ddot{y}$ difficulties to handle in manufacture,

$\ddot{y} \quad$ Demagnetization of PM at high temperature.

In recent years, the use of PMs is more attractive than before, because the performance of PMs is improving and the cost of PM is decreasing. The trends make PM machines with a full-scale power converter more attractive for direct-drive wind turbines. Considering the performance of PMs is improving and the cost of PM is decreasing in recent years, in addition to that the cost of power electronics is decreasing, variable speed direct-drive PM machines with a full-scale power converter become more attractive for offshore wind powers. On the other hand, variable speed concepts with a full-scale power converter and a single- or multiple-stage gearbox drive train may be interesting solutions not only in respect to the annual energy yield per cost but also in respect to the total weight. For example, the market interest of PMSG system with a multiple-stage gearbox or a single-stage gearbox is increasing. [16-18]

\section{RIDE THROUGH TOPOLOGIES FOR GRID CONNECTED VARIABLE SPEED PMSG}

Variable speed use is good for extracting more prime mover power as in wind turbine or for providing optimum efficiency for the prime mover by increasing its speed with power. Variable speed also allows for a more flexible generator system. For wind turbines, a battery may be added to store the extra wind energy that is not momentarily needed for the existing loads or local power grids [18-20]. There are three main ways to handle the necessity of constant DC link voltage at variable speed:

$\ddot{y} \quad$ PMSG with diode rectifier and DC-DC chopper as shown in Fig. 3.

y $\quad$ PMSG with rectifier and DC-DC boost-convertor as shown in Fig. 4.

$\ddot{y} \quad$ PMSG with PWM rectifier with battery for storing the extra wind energy as shown in Fig. 5.

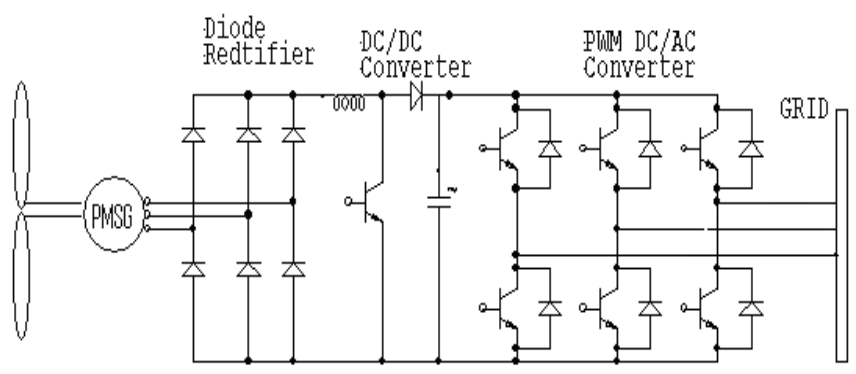

Fig.3. .PMSG with diode rectifier and DC-DC chopper

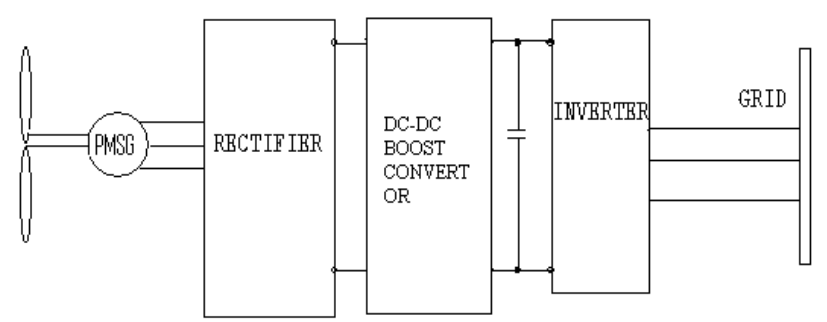

Fig .4. PMSG with rectifier and DC-DC Boost convertor

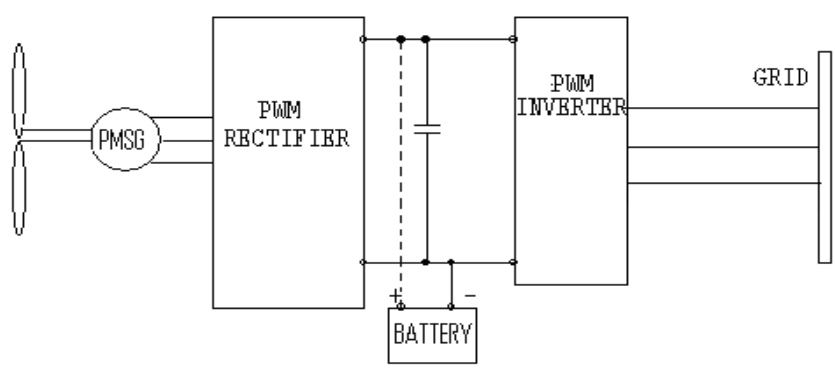

Fig.5. PMSG with PWM rectifier with battery for storing the extra wind energy

\section{MATLAB SimULATION AND MODELING OF THE PROPOSED TOPOLOGY}

The proposed topology has been shown in the Fig.6 and Fig.7. The matlab simulink tool box simpower has been used for getting the required results.

\section{A. Modeling of System}

The supply system consists of three-phase (PMSG) system,. The model of permanent magnet synchronous generator (PMSG) is realized by considering fixed excitation of an alternator. The mathematical representation of all these are given below. 


\section{B. Wind Turbine Modelling}

This block implements a wind energy conversion system. The inputs are actual and desired speed and the output of the block is mechanical power $\left(\mathrm{P}_{\omega}\right)$ The amount of energy that wind carries depends on the wind speed (v), density of the air $(\rho)$, the swept area $\mathrm{A}=(\pi \mathrm{r} 2)$ and the coefficient of performance $(\mathrm{Cp})$. The theoretical limit of $\mathrm{Cp}$ is 0.59 (or 59\%) which is called Betz limit. With current technology, wind turbines can convert up to $50 \%$ of energy in wind into electricity (i.e., $\mathrm{Cp} \sim 0.5$ ).

The amount of power harnessed from the wind of velocity $\mathrm{v}$ is as follows

$$
\begin{aligned}
\mathrm{P}_{\omega} & =1 / 2 * \mathrm{Cp}^{*} \rho^{*}(\pi \mathrm{r} 2)^{*} \mathrm{v} 3 \\
& =1 / 2 \rho \mathrm{AC} \mathrm{C}_{\mathrm{p}} v^{3}
\end{aligned}
$$

\section{Modeling of Permanent Magnet Synchronous Machine}

The permanent magnet synchronous machine block operates in generating or motoring modes. The operating mode is dictated by the sign of the mechanical power (positive for generating, negative for motoring). The electrical part of the machine is represented by a sixth-order state-space model. The model takes into account the dynamics of the stator and damper windings. The equivalent circuit of the model is represented in the rotor reference frame ( $\mathrm{d}-\mathrm{q}$ frame). The following equations are used to express the model of the PMSG as:

$$
\begin{aligned}
& \mathrm{V}_{\mathrm{d}}=\mathrm{R}_{\mathrm{s}} \mathrm{i}_{\mathrm{d}}+\mathrm{p} \varphi_{\mathrm{d}}-\mathrm{w}_{\mathrm{r}} \varphi_{\mathrm{q}} \\
& \mathrm{V}_{\mathrm{q}}=\mathrm{R}_{\mathrm{s}} \mathrm{i}_{\mathrm{q}}+\mathrm{p} \varphi_{\mathrm{q}}+\mathrm{w}_{\mathrm{r}} \varphi_{\mathrm{d}} \\
& V^{\prime}{ }_{f d}=R^{\prime}{ }_{f d} i^{\prime}{ }_{f d}+p \varphi^{\prime}{ }_{f d} \\
& \mathrm{~V}^{\prime}{ }_{\mathrm{kd}}=\mathrm{R}^{\prime}{ }_{\mathrm{kd}} \mathrm{i}^{\prime}{ }_{\mathrm{kd}}+\mathrm{p} \varphi^{\prime}{ }_{\mathrm{kd}} \\
& \mathrm{V}^{\prime}{ }_{\mathrm{kq} 1}=\mathrm{R}^{\prime}{ }_{\mathrm{kq} 1} \mathrm{i}_{\mathrm{kq} 1}+\mathrm{p} \varphi^{\prime}{ }_{\mathrm{kq} 1} \\
& \mathrm{~V}^{\prime}{ }_{\mathrm{kq} 2}=\mathrm{R}^{\prime}{ }_{\mathrm{kq} 2} \mathrm{i}^{\prime}{ }_{\mathrm{kq} 2}+\mathrm{p} \varphi^{\prime}{ }_{\mathrm{kq} 2} \\
& \text { where } \varphi_{d}=L_{d} i_{d}+L_{m d}\left(i_{f d}^{\prime} i_{k d}\right) \\
& \varphi_{\mathrm{q}}=\mathrm{L}_{\mathrm{q}} \mathrm{i}_{\mathrm{q}}+\mathrm{L}_{\mathrm{mq}} \mathrm{i}_{\mathrm{kq}} \\
& \varphi^{\prime}{ }_{\mathrm{fd}}=\mathrm{L}_{\mathrm{fd}} \mathrm{i}_{\mathrm{fd}}+\mathrm{L}_{\mathrm{md}}\left(\mathrm{i}_{\mathrm{d}+} \mathrm{i}^{\prime}{ }_{\mathrm{kd}}\right) \\
& \varphi^{\prime}{ }_{k d}=L^{\prime}{ }_{k d} i^{\prime}{ }_{k d}+L_{m d}\left(i_{d}+i^{\prime}{ }_{f d}\right) \\
& \varphi^{\prime}{ }_{\mathrm{kq} 2}=\mathrm{L}^{\prime}{ }_{\mathrm{kq} 2} \mathrm{i}_{\mathrm{kq} 2}+\mathrm{L}_{\mathrm{mq}} \mathrm{i}_{\mathrm{q}}
\end{aligned}
$$

where the subscripts used are defined as: $d, q$ : $d$ and $q$ axis quantity, r, s: Rotor and stator quantity, 1, m: Leakage and magnetizing inductance, f, k: Field and damper winding quantity. $\mathrm{R}_{\mathrm{s}}$ represents stator resistance, $\mathrm{L}_{\mathrm{ls}}$ stator leakage inductance, $\mathrm{L}_{\mathrm{md}}$ and $\mathrm{L}_{\mathrm{mq}}$ represent $\mathrm{d}$-axis and q-axis magnetizing inductances. $\mathrm{R}_{\mathrm{f}}{ }^{\prime}$ denotes field resistance and $\mathrm{L}_{\mathrm{lfd}}$ ' leakage inductance, both referred to the stator. Damper $\mathrm{d}$-axis resistance $\mathrm{R}_{\mathrm{kd}}$ ' and leakage inductance $\mathrm{L}_{\mathrm{lkd}}$, Damper q-axis resistance $\mathrm{R}_{\mathrm{kq}} 1$ ' and leakage inductance $\mathrm{L}_{\mathrm{lkq} 1}$ ' and the q-axis resistance $\mathrm{R}_{\mathrm{kq} 2}$, and leakage inductance $\mathrm{L}_{\mathrm{lkq} 2}$ ' All these values are referred to the stator. All rotor parameters and electrical quantities are viewed from the stator and are identified by primed variables. The simplified synchronous machine block implements the mechanical system described by:

$$
\begin{aligned}
& \Delta \mathrm{w}(\mathrm{t})=\int(\mathrm{Tm}-\mathrm{Te}) \mathrm{dt} /(2 \mathrm{H})-\mathrm{K}_{\mathrm{d}} \Delta \mathrm{w}(\mathrm{t}) \\
& \mathrm{w}(\mathrm{t})=\Delta \mathrm{w}(\mathrm{t})+\mathrm{w}_{\mathrm{o}}
\end{aligned}
$$

\section{Excitation System}

The excitation system block is a Simulink system implementing an IEEE Type I synchronous machine voltage regulator combined to an exciter. The basic elements that form the excitation system block are the voltage regulator and the exciter. The exciter is represented by the following transfer function between the exciter voltage $V_{f d}$ and the regulator's output $\mathrm{E}_{\mathrm{f}}$

$\mathrm{V}_{\mathrm{fd}} / \mathrm{E}_{\mathrm{f}}=1 /\left(\mathrm{K}_{\mathrm{e}}+\mathrm{sT}_{\mathrm{e}}\right)$

where $\mathrm{K}_{\mathrm{e}}$ represents exciter gain, $\mathrm{T}_{\mathrm{e}}$ exciter time constant. The block uses actual terminal voltage, desired value of terminal voltage and outputs appropriate field voltage to be applied to synchronous alternator. For simulation of PMSG, the excitation is kept constant at 1.0 p.u. in this model of synchronous generator.

\section{E. Modeling of Control Scheme}

The control scheme is mainly used to derive reference source currents, which are used in PWM current controller of VSI of BESS. These are derived in following section.

The reference source currents are having two components, in-phase component and a quadrature component. They are estimated in sequence as follows:

The unit vectors in-phase with $\mathrm{v}_{\mathrm{a}}, \mathrm{v}_{\mathrm{b}}$ and $\mathrm{v}_{\mathrm{c}}$ are derived as: $\mathrm{u}_{\mathrm{a}}=\mathrm{v}_{\mathrm{a}} / \mathrm{V}_{\mathrm{m}} ; \quad \mathrm{u}_{\mathrm{b}}=\mathrm{v}_{\mathrm{b}} / \mathrm{V}_{\mathrm{m}} ; \mathrm{u}=\mathrm{v}_{\mathrm{c}} / \mathrm{V}_{\mathrm{m}}$ where $\mathrm{V}_{\mathrm{m}}$ is the amplitude of the AC terminal voltage at the PCC and can be computed as:

$\mathrm{V}_{\mathrm{m}}=2 / 3 \sqrt{ }\left(\mathrm{v}_{\mathrm{a}}{ }^{2}+\mathrm{v}_{\mathrm{b}}{ }^{2}+\mathrm{v}_{\mathrm{c}}{ }^{2}\right)$

where $\mathrm{v}_{\mathrm{a}}, \mathrm{v}_{\mathrm{b}}$, and $\mathrm{v}_{\mathrm{c}}$ are the instantaneous voltages at PCC and can be calculated as:

$\mathrm{v}_{\mathrm{a}}=\mathrm{v}_{\mathrm{san}}-\mathrm{R}_{\mathrm{s}} \mathrm{i}_{\mathrm{sa}}-\mathrm{L}_{\mathrm{s}} \mathrm{pi} \mathrm{i}_{\mathrm{sa}}$

$\mathrm{v}_{\mathrm{b}}=\mathrm{v}_{\mathrm{sbn}}-\mathrm{R}_{\mathrm{s}} \mathrm{i}_{\mathrm{sb}}-\mathrm{L}_{\mathrm{s}} \mathrm{pi}_{\mathrm{sb}}$

(19)

$\mathrm{v}_{\mathrm{c}}=\mathrm{v}_{\mathrm{scn}}-\mathrm{R}_{\mathrm{s}} \mathrm{i}_{\mathrm{sc}}-\mathrm{L}_{\mathrm{s}} \mathrm{pi} \mathrm{i}_{\mathrm{sc}}$

where $L_{s}$ and $R_{s}$ are per phase source inductance and resistance respectively. $\mathrm{V}_{\mathrm{san}}, \mathrm{V}_{\mathrm{sbn}}$, and $\mathrm{v}_{\mathrm{scn}}$ are the three phase instantaneous input supply voltages at PCC and are expressed as:

$\mathrm{v}_{\mathrm{san}}=\mathrm{v}_{\mathrm{sm}} \sin (\omega \mathrm{t}) ; \mathrm{v}_{\mathrm{sbn}}=\mathrm{v}_{\mathrm{sm}} \sin (\omega \mathrm{t}-2 \pi / 3) ; \mathrm{v}_{\mathrm{scn}}=\mathrm{v}_{\mathrm{sm}} \sin (\omega \mathrm{t}+2 \pi / 3)$

(21)

where $\mathrm{v}_{\mathrm{sm}}$ is the peak value and $\omega=2 \pi \mathrm{f}$ is the frequency of the supply.

The unit vectors in-quadrature with $\mathrm{v}_{\mathrm{a}} \mathrm{v}_{\mathrm{b}}$ and $\mathrm{v}_{\mathrm{c}}$ may be derived by taking a quadrature transformation of the in-phase unit vectors $\mathrm{u}_{\mathrm{a}}, \mathrm{u}_{\mathrm{b}}$ and $\mathrm{u}_{\mathrm{c}}$ as:

$\mathrm{w}_{\mathrm{a}}=-\mathrm{u}_{\mathrm{b}} / \sqrt{ } 3+\mathrm{u}_{\mathrm{c}} / \sqrt{ } 3$

(22)

$\mathrm{w}_{\mathrm{b}}=\sqrt{ } 3 \mathrm{u}_{\mathrm{a}} / 2+\left(\mathrm{u}_{\mathrm{b}}-\mathrm{u}_{\mathrm{c}}\right) /(2 \sqrt{ } 3)$

(23)

$\mathrm{w}_{\mathrm{a}}=-\sqrt{ } 3 \mathrm{u}_{\mathrm{a}} / 2+\left(\mathrm{u}_{\mathrm{b}}-\mathrm{u}_{\mathrm{c}}\right) /(2 \sqrt{ } 3)$

The quadrature component of the reference source currents is computed as:

The voltage error $\mathrm{V}_{\mathrm{er}}$ at $\mathrm{PCC}$ at the nth sampling instant is as: $\mathrm{V}_{\mathrm{er}(\mathrm{n})}=\mathrm{V}_{\mathrm{ref}(\mathrm{n})}-\mathrm{V}_{\mathrm{m}(\mathrm{n})}$

The output of the PI controller at the nth sampling instant is expressed as:

$\mathrm{I}^{*}{ }_{\mathrm{smq}(\mathrm{n})}=\mathrm{I}_{\text {smq(n-1) }}+\mathrm{K}_{\mathrm{p}}\left\{\mathrm{V}_{\mathrm{er}(\mathrm{n})}-\mathrm{V}_{\mathrm{er}(\mathrm{n}-1)}\right\}+\mathrm{K}_{\mathrm{i}} \mathrm{V}_{\mathrm{er}(\mathrm{n})}$

where $\mathrm{K}_{\mathrm{p}}$ and $\mathrm{K}_{\mathrm{i}}$ are the proportional and integral constants, respectively of the proportional integral (PI) controller and the superscript represents the reference quantity.

The quadrature components of the reference source currents are estimates as:

$\mathrm{i}^{*}{ }_{\mathrm{saq}}=\mathrm{I}_{\mathrm{smq}} \mathrm{W}_{\mathrm{a}} ; \quad \mathrm{i}^{*}{ }_{\mathrm{sbq}}=\mathrm{I}_{\mathrm{smq}} \mathrm{W}_{\mathrm{b}} ;{ }_{\mathrm{I}}{ }_{\mathrm{scq}}=\mathrm{I}^{*}{ }_{\mathrm{smq}} \mathrm{W}_{\mathrm{c}}(27)$ The in-phase component of the reference source currents is computed as:

$\mathrm{i}^{*}{ }_{\text {sad }}=\mathrm{I}^{*}{ }_{\text {smd }} \mathrm{u}_{\mathrm{a}} ; \mathrm{i}^{*}{ }_{\mathrm{sbd}}=\mathrm{I}^{*}{ }_{\mathrm{smd}} \mathrm{u}_{\mathrm{b}} ; \quad \mathrm{i}^{*}{ }_{\mathrm{scd}}=\mathrm{I}^{*}{ }_{\text {smd }} \mathrm{u}_{\mathrm{c}}(28)$ where $\mathrm{I}^{*}$ smd is considered fixed value corresponding to the constant source current for load leveling.

Reference source currents are computed as the sum of the 
in-phase components of the reference source currents and the quadrature components of the reference source currents given as:

$\mathrm{i}_{\text {sa }}=\mathrm{i}_{\text {saq }}+\mathrm{i}_{\text {sad }} ; \mathrm{i}_{\mathrm{sb}}=\mathrm{i}_{\mathrm{sbq}}+\mathrm{i}_{\mathrm{sbd}} ; \mathrm{i}_{\mathrm{sc}}=\mathrm{i}_{\text {scq }}+\mathrm{i}_{\mathrm{scd}}$

These source reference currents are compared with the sensed source currents in PWM current controller. The current errors of all the three phases are amplified. If the amplified reference source current error signal, $i_{\text {saerr, }}$ is greater than the triangular wave carrier signal, switch $S_{1}$ is $\mathrm{ON}$ and switch $\mathrm{S}_{4}$ is $\mathrm{OFF}$, and the value of $\mathrm{SA}$ is 1 . When the amplified reference source current error signal is less than the triangular wave carrier signal switch $\mathrm{S}_{1}$ is OFF and switch $\mathrm{S}_{4}$ is $\mathrm{ON}$, and the value of SA is 0 . Similar logic applies to other phases.

\section{Simulation RESUlts}

The Figs. 8-12 show the voltages on inverter side $\left(\mathrm{V}_{\mathrm{abc} \_ \text {inv }}\right)$, currents on inverter side $\left(\mathrm{I}_{\mathrm{abc} \_ \text {inv }}\right)$, voltage at point of common coupling $(\mathrm{PCC})\left(\mathrm{V}_{\mathrm{pcc}}\right)$, current at $\mathrm{PCC}\left(\mathrm{I}_{\mathrm{pcc}}\right)$, grid voltages $\left(\mathrm{V}_{\text {grid }}\right)$, grid currents $\left(\mathrm{I}_{\text {grid }}\right)$ and the $\mathrm{DC}$ - link voltage $\left(\mathrm{V}_{\mathrm{dc}}\right)$. The rating of the PMSG is given in the Appendix.

\section{A. Performance of the PMSG based AC-DC-AC conversion system during healthy conditions:}

The wind driven PMSG is run at $94 \mathrm{rpm}$. The out voltage is $150 \mathrm{~V}$ at 60 hertz. This variable voltage and variable frequency output is converted to constant voltage and constant frequency source. The Fig. 8 shows the performance of the PMSG during healthy conditions.

\section{B. Performance of the PMSG based AC-DC-AC conversion system during balanced and fault conditions:}

A balanced three-phase symmetrical fault on the load bus was simulated at 1.0 seconds. The fault was cleared at 1.14 seconds. Thus voltage sag of $140 \mathrm{~ms}$ was simulated. During the fault condition the proposed system stay connected to the local grid feeding active and reactive power. Fig. 9 shows the performance of PMSG during symmetrical fault conditions.

An unsymmetrical fault (phase to phase and phase to ground) on the load bus was simulated at 1.0 seconds. The fault was cleared at 1.14 seconds. Thus voltage sag of $140 \mathrm{~ms}$ was simulated. During the fault condition the proposed system stay connected to the local grid feeding active and reactive power. Figs.10-12 respectively shows the performance of PMSG during unsymmetrical fault conditions.

\section{CONCLUSION}

The output power of direct-driven wind energy conversion system (WECS) will be limited during grid voltage sag, but the operation of wind turbine will not be influenced by adding damp load in DC-side, then the capability of low voltage ride through (LVRT) may be enhanced. Full power back-to-back PWM converter is adopted in direct-driven variable-speed constant frequency WECS using permanent magnet synchronous generator (PMSG), which can effectively improve system efficiency. The effects of symmetrical and unsymmetrical fault are investigated. The whole system modeling of converters is realized. Then the simulation model of converters is built based on Matlab7.3/Simulink6.5, and the characteristic during grid voltage sag is simulated; the validity of the model and analysis is verified by simulation, and the results show that direct-driven WECS have good fault ride through capability. In the case of symmetrical and unsymmetrical fault conditions in grid network, the ac voltage of PCC can meet the basic requirements of grid network concerning voltage. On the other hand, according to simulation results, variable speed driven PMSG is not significantly impacted in abnormal conditions. So it can remain connecting to the grid during and after grid short circuit fault. The inverter is controlled so as to meet IEEE standard 1547 requirements for connection of distributed generation to the local grid. The simulated results validate the proposed topology.

\section{APPENDIX}

Permanent Magnet Synchronous Generator: 3-Phase, $300 \mathrm{~V}, 60 \mathrm{~Hz}, 3000 \mathrm{rpm}$, 4-pole

Electromagnetic Torque : $\quad 0.8 \mathrm{Nm}$

Stator Resistance $\left(\mathrm{R}_{\mathrm{S}}\right) \quad$ : $\quad 18.7 \Omega$

Inductance : $\mathrm{Ld}(\mathrm{H})=\mathrm{Lq}(\mathrm{H}) \quad: \quad 0.02682 \mathrm{H}$

Flux induce by magnets $\quad: \quad 0.1717 \mathrm{wb}$

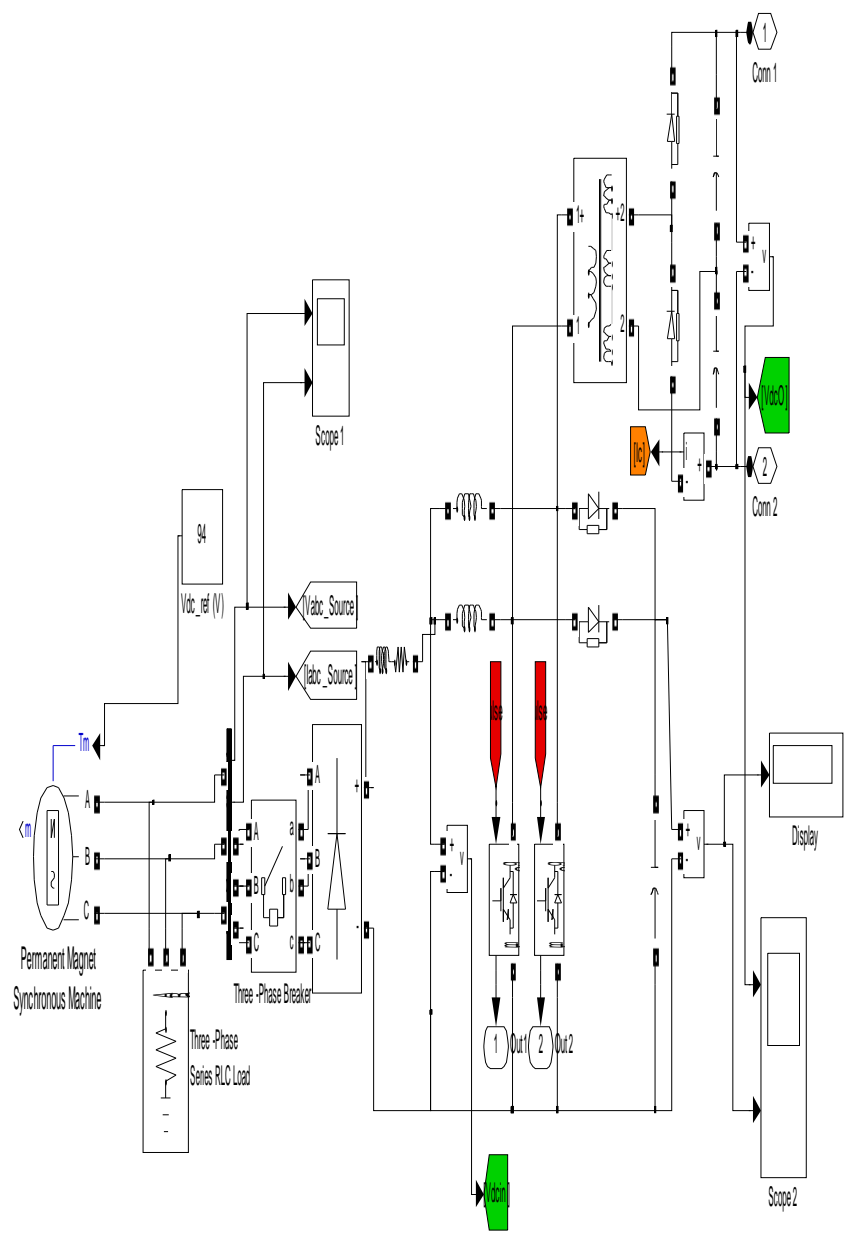

Fig.6. MATLAB Simulated model of PMSG connected to local grid 


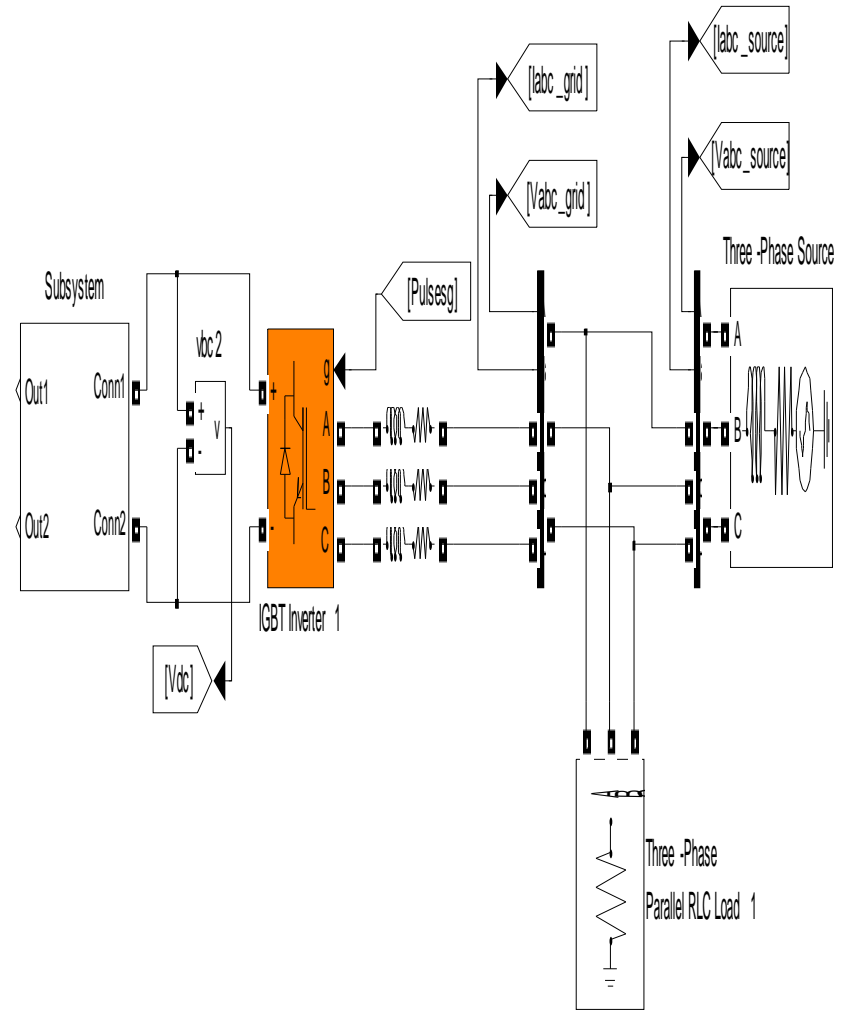

Fig..7. Subsystem used in MATLAB Simulated model of PMSG

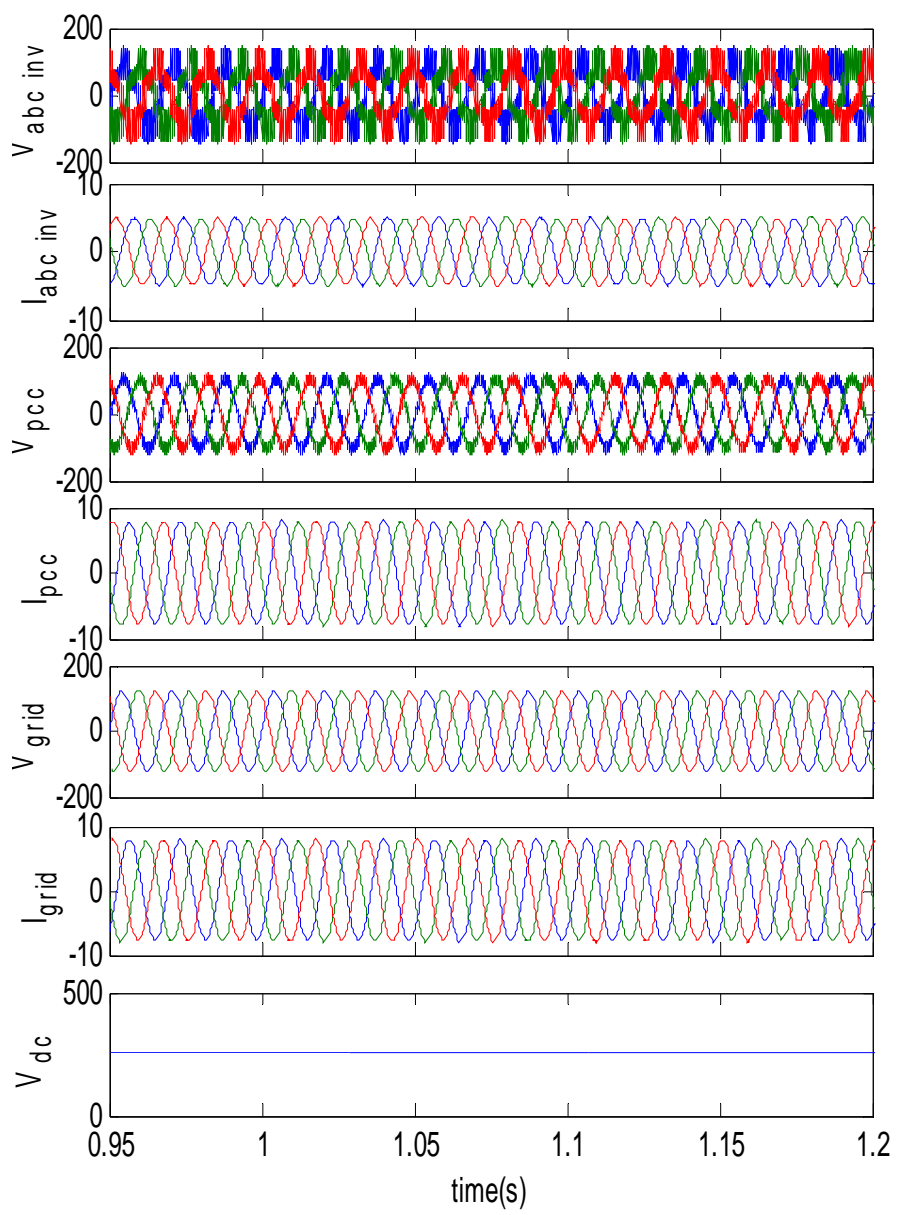

Fig..8. Variation of inverter voltages, currents, during healthy operation

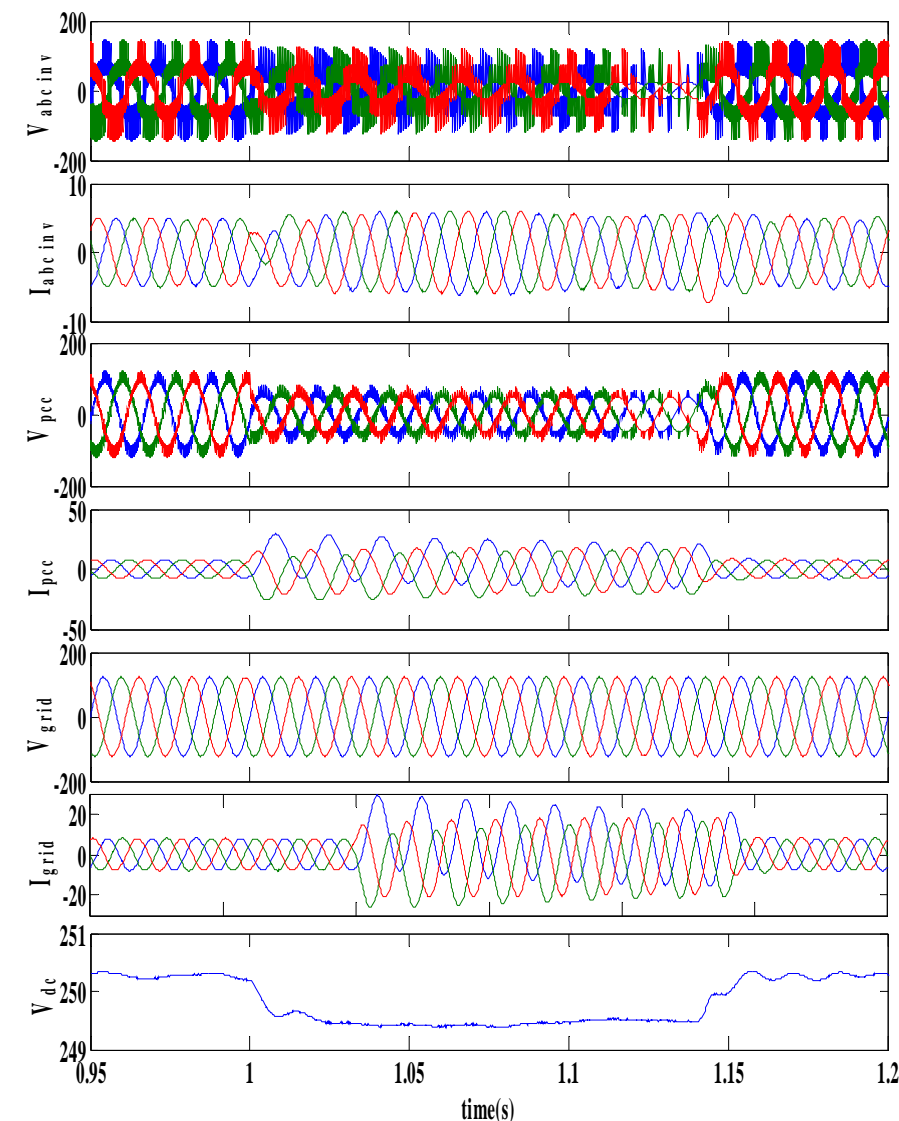

Fig..9. Variation of inverter voltages, currents, during symmetrical fault ridethrough of PMSG

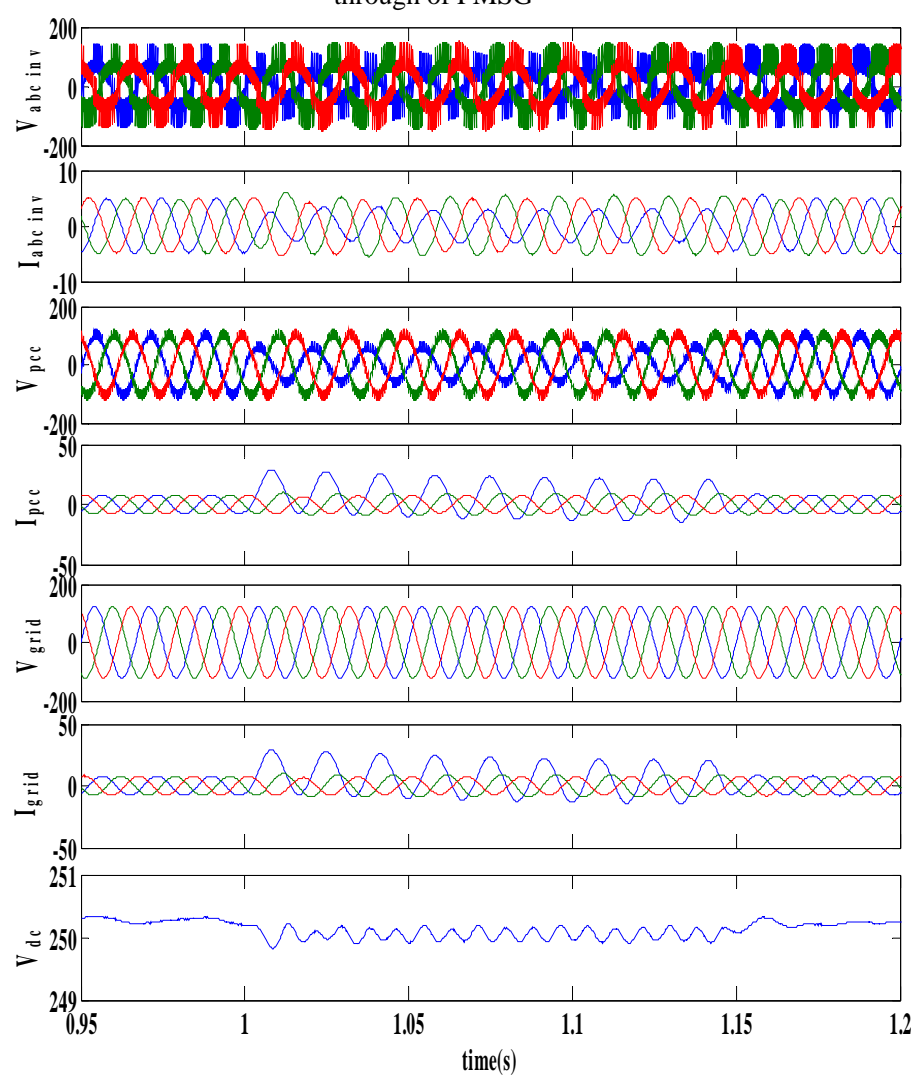

Fig...10. Variation of inverter voltages, currents, during unsymmetrical (one phase to ground) fault ride- through of PMSG 


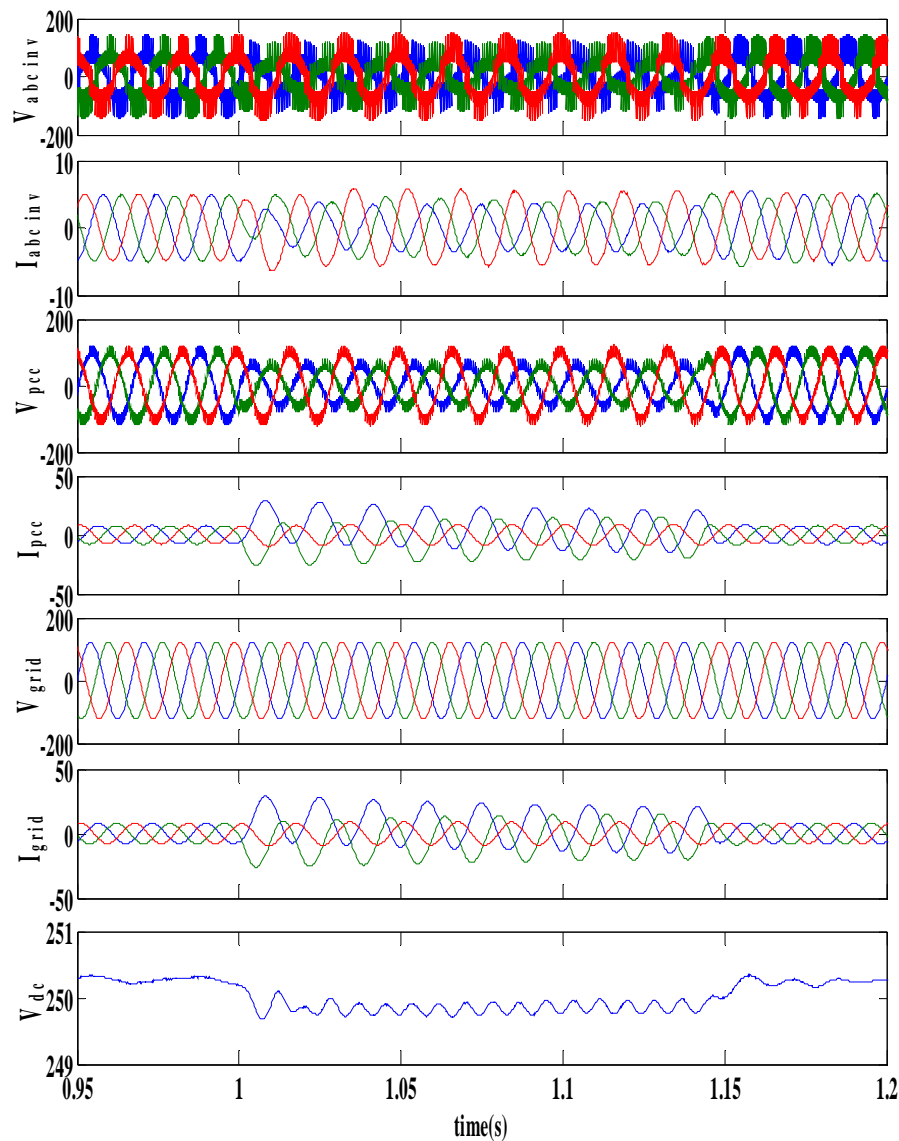

Fig...11. Variation of inverter voltages, currents, during unsymmetrical (two phase to ground) fault ride- through of PMSG.
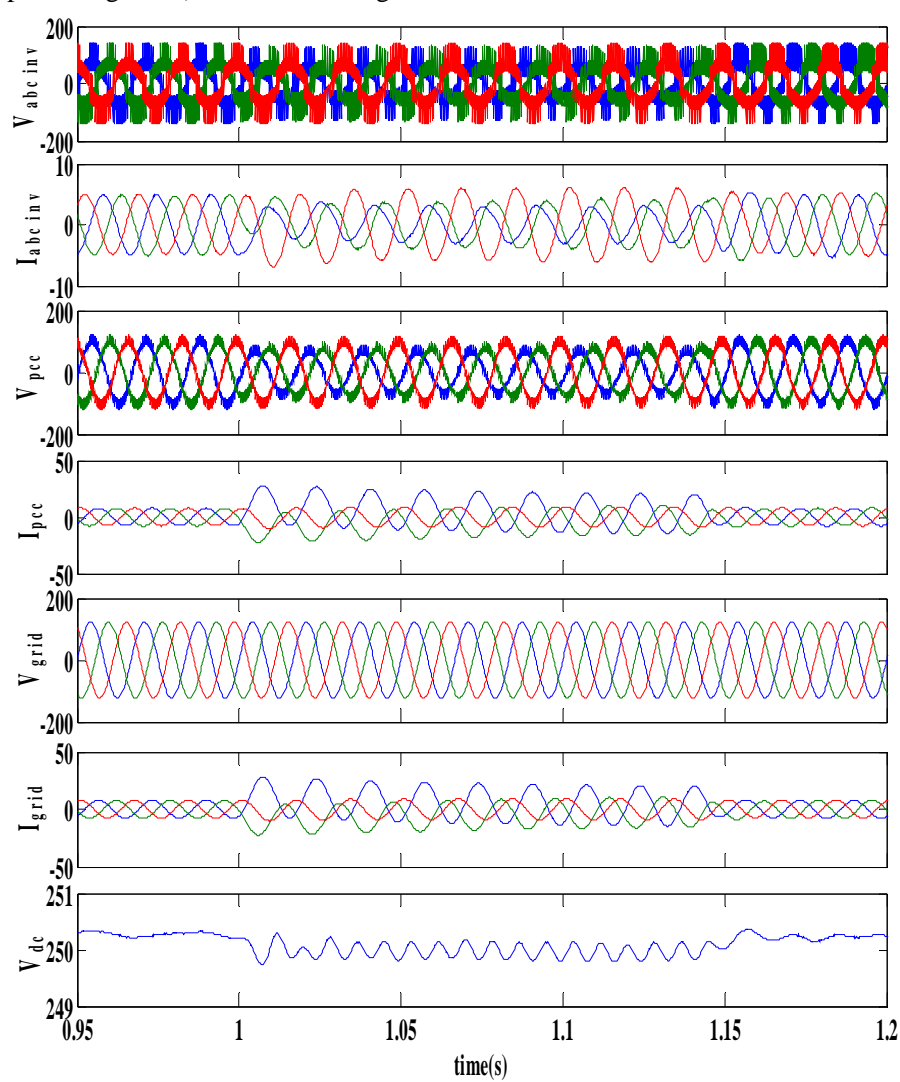

Fig.12. Variation of inverter voltages, currents, during unsymmetrical (phase to phase) fault ride- through of PMSG

\section{REFERENCES}

[1] IEEE Recommended Practices on Monitoring Electric Power Quality, IEEE Std.1159, 1995.
[2] Draft Standard for Interconnecting Distributed Resources with Electric Power Systems, IEEE std. P1547/07.

[3] N. Jenkins, R. Allan, P. Crossley, D. Kirschan and G. Strbac, Embedded Generation, IEEE Power and Energy Series 31, 2000.

[4] Ghosh and G. Ledwich, Power Quality Enhancement Using Custom Power Devices. Kulwer Academic, 2002.

[5] Gipe, P. Wind power', Chelsea Green Publishing Company, Post Mills, Vermount, USA, 1995.

[6] C. Ong "Dynamic Simulation of Electric Machines Using MATLAB/Simulink" Editorial "Prentice Hall", 1998.

[7] S. Santoso, H. W. Beaty, R. C. Dugan, and M. F. McGranaghan, "Electrical Power Systems Quality," 2d ed: McGraw Hill, 2002.

[8] I.Erlich, W.Winter and A.Disttrich,"Advanced Grid Requirements for the Integration of Wind Turbines into the German Transmission System," in Power Engineering Society General Meeting, 2006, IEEE, 18-22 June 2006, p.7pp.

[9] C. Jauch, P. Sorensen, and B. Bak-Jensen, "International review of grid connection requirements for wind turbines," in Nordic wind power conference, Goteborg, March 2004

[10] C. Jauch, J. Matevosyan, T. Ackermann, and S. Bolik, "International comparison of requirements for connection of wind turbines to power systems," Wind Energy, vol. 8, pp. 295-306, 2005.

[11] Seman, S.; Niiranen, J.; Arkkio, A.' 'Ride-Through Analysis of Doubly Fed Induction Wind-Power Generator Under Unsymmetrical NetworkDisturbance', Power Systems, IEEE Transactions on Volume 21, Issue 4, Nov. 2006 Page(s):1782 - 1789 Digital Object Identifier 10.1109/TPWRS.2006.882471

[12] Alvaro Luna, Pedro Rodriguez, Remus Teodorescu, Freede Blaabjerg," Low voltage ride through strategies for SCIG wind turbines in distributed power generation systems," IEEE Transaction , pp-2333-2339.

[13] Bansal, R.C., Bhatti, T.S., and Kothari, D.P. "On some of the design aspects of wind energy conversion systems", Int. Journal of Energy Conversion and Management, Nov. Vol. 43, No. 16, pp. 2175-2187,2002

[14] Muller, S., Deicke, M., and Doncker, R.W.D. (2002) “Doubly fed induction generator systems" IEEE Industry Applications Magzine, May/June, pp. 26- 33.

[15] Singh, B. "Induction generator-a prospective" Electric Machines and Power Systems, Vol. 23, pp. 163-177,1995.

[16] Zouaghi, "Variable Speed Drive modelling of Wind Turbine Permanent Magnet Synchronous Generator,' ICREP'04 International Conference on Renewable Energy and Power Quality, Barcelona, Spain, 2004.

[17] Z. Chen, E. Spooner, "Grid interface options for variable speed, permanent-magnet generators," IEEE Proc.-Electro. Power Appl., Vol. $145, \mathrm{~N}^{\circ} 4$, July 1998 .

[18] Chinchilla, M. Arnaltes, S. Burgos, J.C. "Control of permanent-magnet generators applied to variable-speed wind-energy systems connected to the grid" Energy conversion, ieee transactions on March 2006 Volume: 21, Issue: 1On page(s): 130- 135ISSN: 0885-8969

[19] Molina, M.G.; Mercado, P.E.," A new control strategy of variable speed wind turbine generator for three-phase grid-connected applications", Transmission and Distribution Conference and Exposition: Latin America, 2008 IEEE/PES 13-15 Aug. 2008 Page(s): $1-8$

[20] D.C. Aliprantis, S.A. Papathanassiou, M.P. Papadopoulos, A.G.Kaladas, "Modeling and control of a variable-speed wind turbine equipped with permanent magnet synchronous generator," Proc. Of ICEM, Vol.3, pp.558-562, 2000.

\section{BIOGRAPHIES}

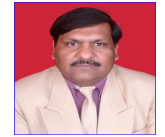

Rajveer Mittal received his B.E degree in Electrical Engineering from R.E.C, Kurukshetra ,Haryana, India in 1987, the M.E degree in Electrical Engineering (Instrumentation \& Control) from Delhi College of Engineering, Delhi University, Delhi, India in 2003, and is currently pursuing the Ph.D. degree in the research area of "Power Quality Studies of Wind Energy Systems" of Electrical Engineering from N.I.T, Kurukshetra , Haryana, India. Currently, he is working as a Asst.Prof. in EEE Department with the Maharaja Agrasen Institute of Technology, Rohini, Delhi under GGSIP University, Delhi, India. His research interests include power quality, motor drives, and Renewable energy. 
Dr.K.S.Sandhu received the B.Sc. Engg. (Electrical), M. Sc. (Electrical) and PhD (Electrical Machines) degrees from Regional Engineering College, Kurukshetra University, Kurukshetra, India in 1981, 1985 and 2001, respectively. He joined the Electrical Engineering Department of Regional Engineering College, Kurukshetra, as Lecturer in January 1983. Currently, he is Professor in Electrical Engineering Department, National Institute of Technology, Kurukshetra India. He has number of publications in the area of electrical machines \& induction generators. His areas of interest include electrical machines, wind energy conversion, power quality, power systems and artificial intelligence.

Dr.D.K.Jain received his B.Tech, M.Tech and Ph.D. degree in Electrical Engineering from R.E.C, Kurukshetra, India. Currently, he is working as Director Guru Prem Sukh Memorial College of engineering under GGSIP University, Delhi, India. He has number of publications in the area of electric power quality, adjustable speed drive and induction generators. His research interests include electric power quality, motor drives, and renewable energy systems. 